\title{
Where the Wild Things are: Learning from Tunnerminnerwait and Maulboyheener
}

Standing by Tunnerminnerwait and Maulboyheenner, Brook Andrew and Trent Walter ${ }^{1}$

Reviewed by

Jayson Cooper

1 Standing by Tunnerminnerwait and Maulboyheenner is a commemorative marker by artists Brook Andrew and Trent Walter, commissioned by the City of Melbourne in early 2016, and opened publicly on 11 September 2016.

Journal of Public Pedagogies, Number 2, 2017

Published by Public Pedagogies Institute: www.publicpedagogies.org

Open Access article distributed under a CC-BY-NC 4.0 license

URL http://jpp.vu.edu.au/

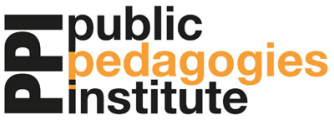


Places are pedagogical; and they teach through a range of ways. In recent public pedagogy discourse Biesta (2014) puts forth three forms of public pedagogy. These three forms of publicness are; pedagogy for the public; pedagogy of the public; and pedagogy in the interests of publicness. What Biesta offers with these views of pedagogy in the public sphere, is an understand of the ways we teach and learn in public places, and how that pedagogy is performed. In particular a pedagogy in the interest of publicness sees grassroots community led pedagogy that acts in the interest of publicness. This provides a lens to examine how pedagogy and knowledge is held in public spaces.

When thinking about the public, Savage (2014) contributes by directing our thinking about how teaching and learning lives in the public sphere. Savage's idea of the concrete public views the public space as being a spatially bound site, 'such as urban streetscapes or housing estates' (p. 87). These spaces are political, but not in the same way Savage defines political publics and popular publics. Concrete publics are clearly defined in boundary and space; these forms of public have borders. Whereas Savage's definition of popular and political publics operate within different parameters and incite ideas about the various ways the public sphere operates. In naming these three forms of public Savage asks public pedagogues to consider which public and whose public are involved in the teaching and learning of these spaces.

In journal articles books are usually reviewed; in this review I explore a concrete public site and its art following Savage's (2014) idea-that is geographically bound pubic spaces are pedagogical — as opposed to a book review. In doing this the narrative and site of the first hanging in Melbourne becomes a pedagogical contact zone that can also be read alongside Beista's (2014) concept, in the interest of publicness. In doing this the site where the first hanging in Melbourne holds memory, just like one would find with other

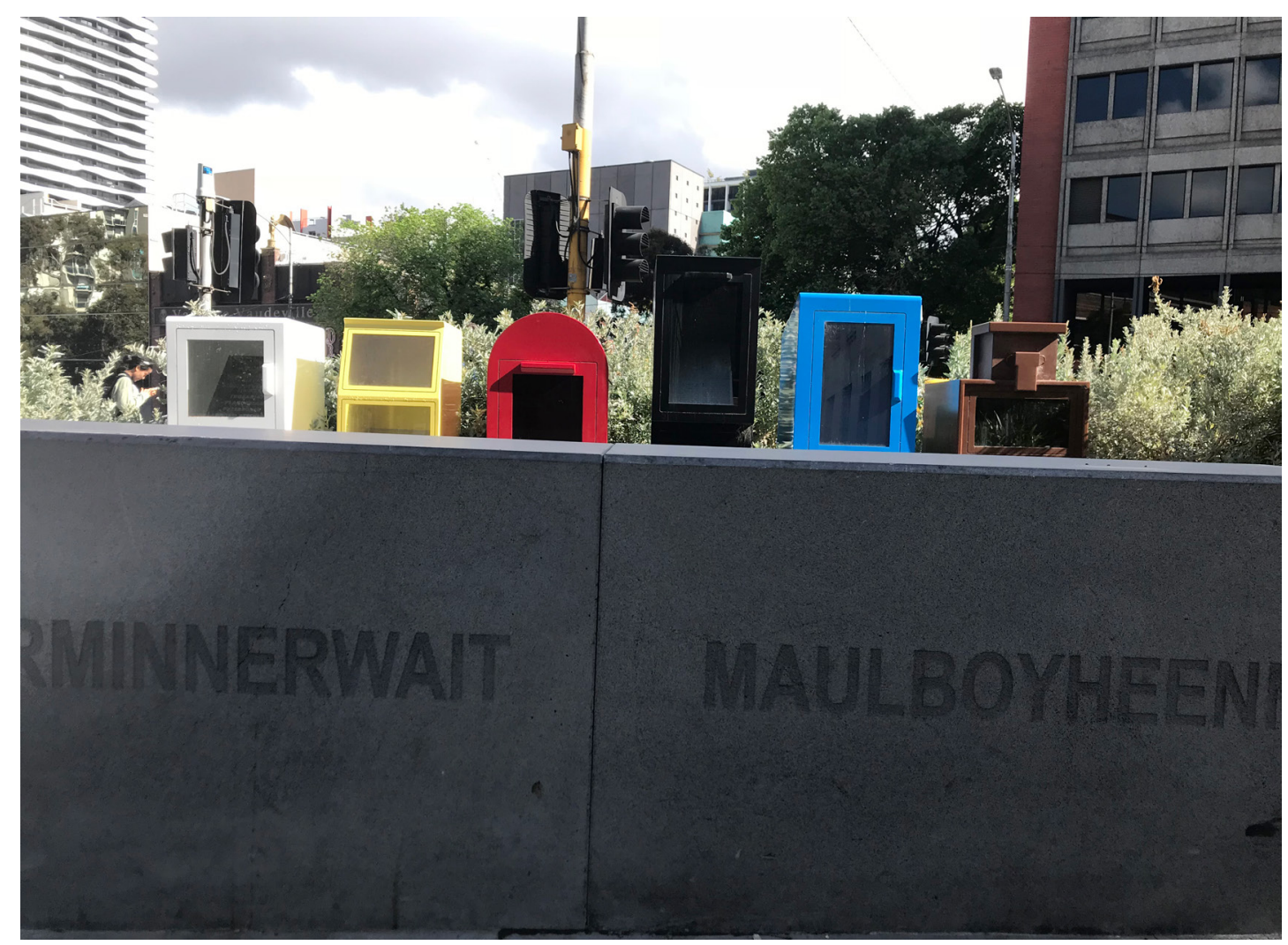

Figure 1: Standing with Tunniminnerwait and Maulboyheener (photograph: Jayson Cooper, 2017) 
historical sites, like the old Gaol, or with war memorials. These places are always ready, always pedagogical, and carry their own sense of agency, memory and consciousness. Giroux (2004) states that 'matters of agency, consciousness, pedagogy, and rhetoric are central to any public discourse' (p. 59), and in this small hidden away place there is an embodiment of these ideas.

Melbourne is known for its laneways and hidden locations throughout the city area. One of these places hides in the northern section of Melbourne city. Wedged in-between RMIT (one of Melbourne's universities) and The Old Melbourne Gaol along busy Franklin Street, is a small park with a silent bluestone swing, permanently fused to the ground. Brightly coloured newsstands, with information contained behind Perspex screens inform the public about the history of this place. This location is where the first public execution took place. It is a war memorial; a memory; a part of the founding stories and events of early Melbourne and Australia; a reminder of the tensions between Aboriginal and non-Aboriginal Australia. This space is what Savage calls a concrete public. It is geographically and historically bound.

\section{Storying the Terrain}

All places have stories; some stories are about love, passion and memory, others hold different memories that do not bring joy into the narrative, but speak of dark times. The Australian state known as Victoria was established by a man named John Batman. Batman, an entrepreneur who sought his fortune in the southern waters and lands of the Australian continent. He took occupation of the area now known as Melbourne City and saw this location as the place for a village. This occupation of land invited squatters, surveyors and ex-convicts to enter a race to capture, capitalise and seize what they referred to as 'empty country'. A false treaty was made between the traditional owners of this place, the Wurundjeri of the Kulin Nation. In this treaty, known as the Batman Treaty, knives, flour, axes and other bits and pieces were traded for a large parcel of land. This treaty was rebuked by the reigning British Crown for it usurped the foundations of Australian colonisation, Terra Nullius (land not inhabited by people, the great southern empty land). Terra Nullius does not recognise Aboriginal ownership of land, and therefore Batman's treaty has no legal status in the eyes of the Crown. Batman acted on his own accord and despite the Crown rejecting and calling this treaty void, Batman opened the floodgates for Victoria to have tsunami after tidal wave of colonial onslaught.

Quarries, industry, and buildings were constructed, rivers and wetlands were reconstructed, and the Murnong (the yam daisy) sent to the brink of extinction, and the city of Melbourne continues to expand. Melbourne has always been an important place for Aboriginal people, in particular the Wurundjeri and Boonwurrung peoples of the Kulin Nation. The arrival of Batman, as well as the whalers and sealers prior, brought drastic changes to Melbourne and Victoria more generally. Melbourne become a central base in the south of mainland Australia. Batman wasn't the first European to move through these southern waters of Australia. Like Batman many opportunistic men sought their fortunes in the oceans. Sealers and whalers were making a bounty plucking sea life from the oceans. Common practice for these seafaring men was to take Aboriginal people with them on their journeys. They used these men as intermediaries, and they used the women as slaves. The arrival of Europeans in Australia is a story of displacement, resistance and human rights, and lack thereof (a struggle that continues today for Australia as a nation).

George Augustus Robinson was working in Tasmania as the Protector of Aborigines and was instrumental in Tasmania's Black Wars, where he relocated Aboriginal men, 
women and children to Flinders Island. This relocation was the result of their surrender to the Black Wars of Tasmania in 1828 - 32. Robinson used the famous Truganini and her husband Woorraddy to negotiate the laying down of arms for safe passage to Flinders Island, an island between Tasmania and Victoria. Robinson used his negotiations with Aboriginal people as a way to further his career and to take up post as Chief Aborigine Protector in Victoria. In this role Robinson took a group of Tasmania Aboriginal people with him to Melbourne to assist him. Truganini, her husband Woorrady, Pyterruner, Planobeena, Tunnerminnerwait and Maulboyhenner were part of the 16 Tasmanian Aboriginal people (Palawa) taken from Flinders Island by Robinson.
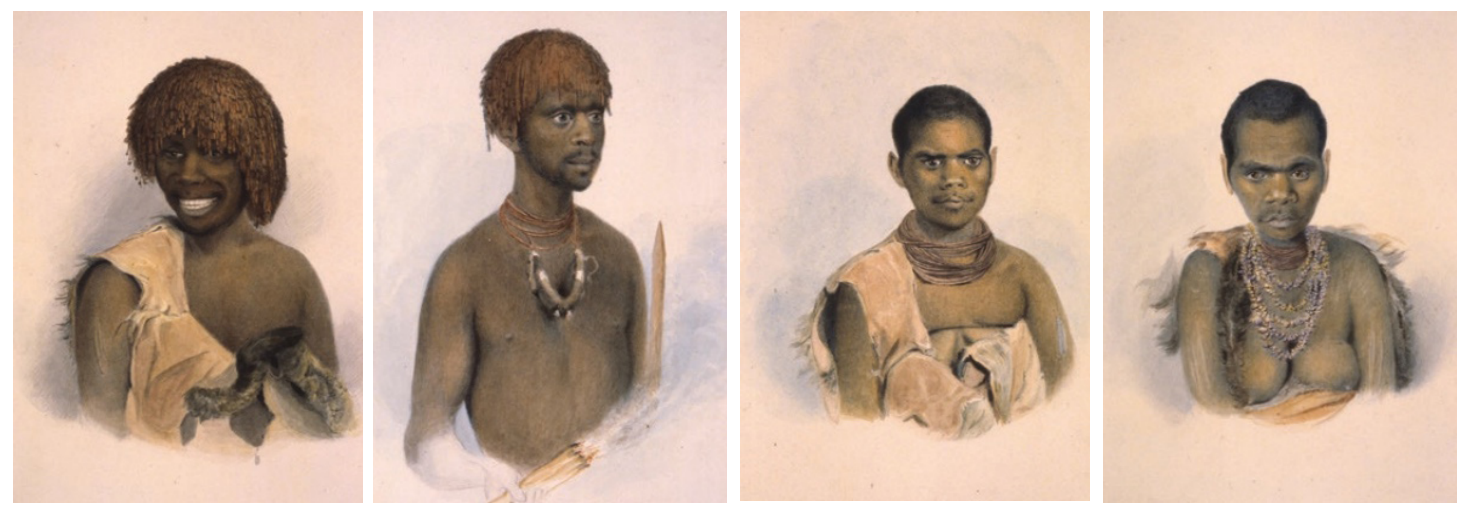

Figure 2: From left to right Tunnerminnerwait, Maulboyhenner, Planobeener and Tuganini,

(Land \& City of Melbourne, 2014)

Tunnerminnerwait along with Truganini, Planobeena, Pyterruner and Maulboyhenner, fled from Robinson's camp as a group of freedom fighters and warriors; resisting colonial occupation and warfare. These Palawa people took up resistance. Throughout the southern districts of Melbourne Tunnerminnerwait, Maulboyhenner, Planobeena, Pyterruner and Truganini, stole firearms and other goods and conducted raids on white settlements. Eventually the police tracked down the group with the aid of the newly formed Native Police Force. The two men Tunnerminnerwait and Maulboyhenner were sentenced to death for the murder of two whale-hunters in the Western Port district of Victoria. The three women were sent back to Flinders Island.

\section{First Public Execution in the Colony of Victoria}

The first public execution in Melbourne, Victoria was the hanging of Tunnerminnerwait and Maulboyhenner. They were tried with the murder of two whale-hunters and hanged on 20 January 1842. The three women Truganini, Pyterruner and Planobeena were deported back to Flinders Island along with Truginini's husband who died on passage. The day of the hanging, large numbers of the population of colonial Melbourne gathered at the corners of Bowen Street and Franklin Street to watch the execution. With over 5000 people in attendance the place known as 'Gallows Hill' held a fanfare spectacle. Spectators came to witness the first public execution in Victoria, with some settlers jumping on the coffins of the deceased to get a closer look. The government used this spectacle to deter further acts of civil disobedience; their stance was firm and cold blooded. For the on looking Kulin and Aboriginal community of early day Melbourne they were presented with a macabre scene. Tunnerminnerwait and Maulboyhenner were buried in the Old Melbourne Cemetery which is now beneath the Queen Victoria Markets. 


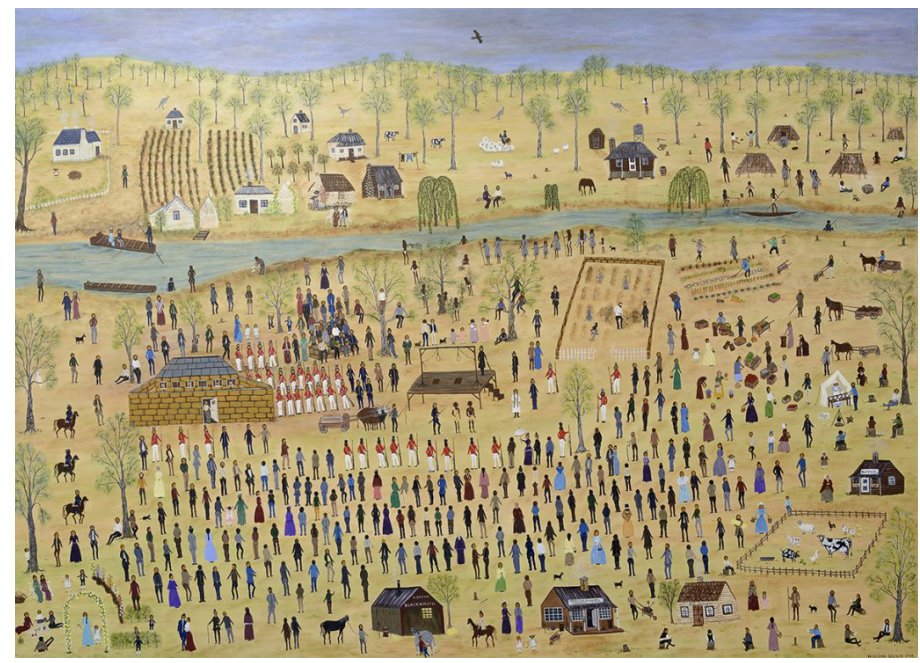

Figure 3: Tunnerminnerwait and Maulboyheenner, by Marlene Gibson (City of Melbourne, 2017a)

\section{Remembering Narratives: Where the Wild Things Are}

In 2013 the City of Melbourne began to began retelling the story of Tunnerminnerwait and Maulboyhenner (Land \& City of Melbourne, 2014). From this project local artists Brook Andrew and Trent Walker generated a permanent installation (war memorial) to commemorate and remember these two men called, Standing with Tunnerminnerwait and Maulboyhenner. This installation is a permanent marker 'that is experimental and empowering' (City of Melbourne, 2017b). Inviting the public to embrace the processes of teaching, learning and remembering through an experiential public art encounter. Remembering and making vocal the stories that get shrouded in the dust of history's pages, stories that often linger in the margins of national memory. The Tunnerminnerwait and Maulboyhenner site is a powerful location for teaching and learning. This is a story and site of conflict, and in modern day urban landscapes, the wars and violence directed toward Aboriginal people barely enter the collective narrative. This clashing of culture and of law is represented through the artist's symbolism and use of objects in this space. Overlaid on the site where the two men were hanged, a heavy swing made of bluestone sits on the ground whilst being suspended by chains. Behind a row of newspaper stands tell the public stories about Aboriginal and Settler histories of Melbourne and Tasmania. This location was known as Gallows Hill. The bluestone swing becomes 'the tomb, laden with memory and history' (City of Melbourne, 2017b) and in a dark way the whole site becomes a tomb, a time capsule and a reflection of colonial Melbourne.

Hedged in between modern and old, the Old Melbourne Gaol carefully crafted from bluestone by convicts sits on the opposite side of the space. This space not only blurs history, it blurs time, and places (European and non-European), yet risks the danger of becoming part of the furniture. Like an island in the stream most pedestrians walk past this space as they hurry from one destination to another. Despite this, Standing with Tunnerminnerwait and Maulboyheenner, quietly remembers, it stands strong. In this way this small island holds onto the ongoing and transformative connection to country held by South-east Aboriginal Australians. Towering behind, William Barak an important Wurundjeri man, is etched into a building's façade as another quiet reminder of Aboriginal Victoria and their narratives. This small concrete public becomes a pedagogical contact zone between human and non-human, Aboriginal and non-Aboriginal, past and present. 

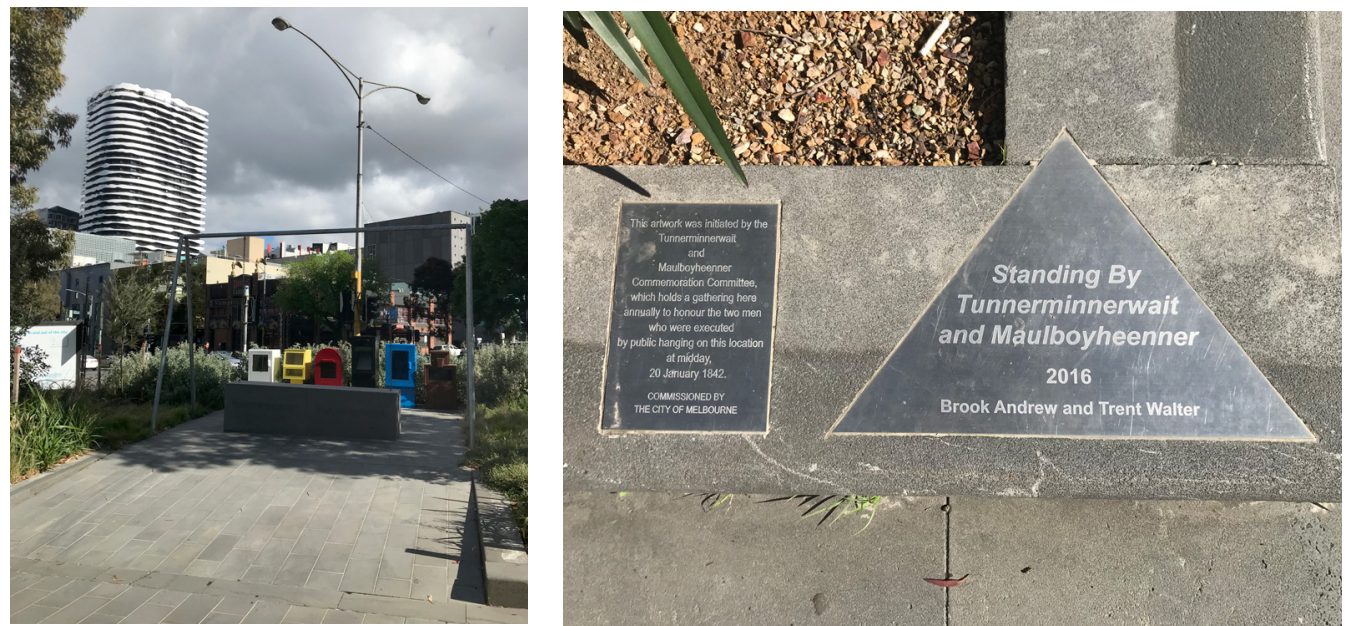

Figure 4: Standing with Tunnerminnerwait and Maulboyhenner
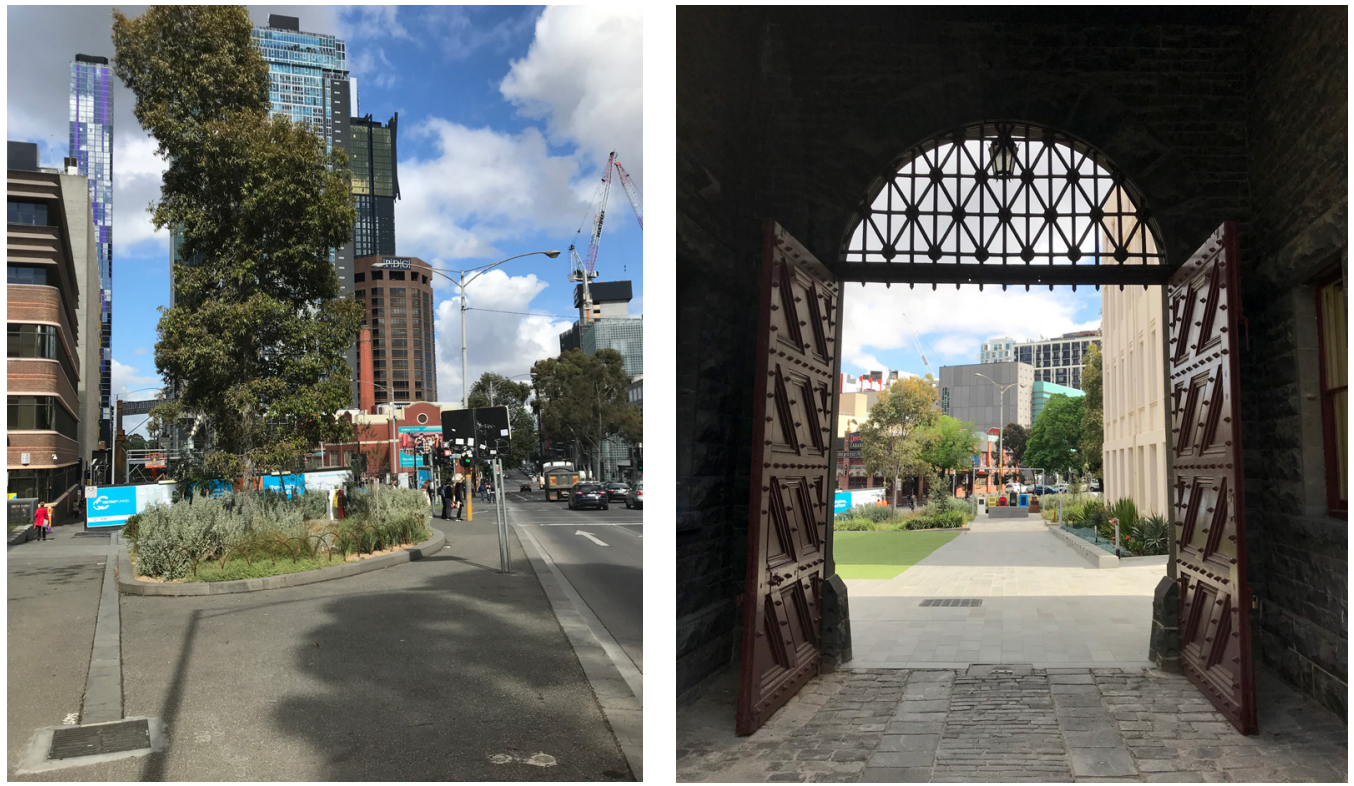

Figure 5: Looking at the site from Franklin Street and looking out from the Old Gaol building (now part of RMIT) (Photographs by Jayson Cooper)

\section{Lest We Forget}

Public Pedagogy is enacted in the interest of publicness (Biesta, 2014) by marking, inscribing, and scratching these stories into our everyday landscapes. Made in collaboration between the City of Melbourne and the local Aboriginal community this public space is created in the interest of publicness, it connects to the political, and historical interactions deeply into the public sphere. They speak from a marginalised history that has been hidden from the national memory. It teaches in a radical way inviting the public to listen, watch, relate and decolonise. This arts-based form of public pedagogy invites international visitors and local members of the Melbourne community a chance to interact with and learn about the history of Australia, Victoria, and Melbourne. To engage with knowledge that contests the single narrative of colonial Australia. Brook Andrews and Trent Walker have created a public site of resistance to colonialism and provoke critical views on how we know and benefit from this past and present bound togetherness (Dening, 2006). Tunnerminnerwait and Maulboyhenner speak from beyond the gallows, giving Melbournians a deeper understanding of the places their lives are entangled with. 


\section{References}

Biesta, G 2014, 'Making Pedagogy Public: for The Public, of the Public, or in the Interest of Publisness?' in J. Burdick, J. A. Sandlin, \& M. P. O’Malley (Eds.), Problematizing Public Pedagogy, Routledge, New York, pp. 15-25

City of Melbourne. (2017a), Executed on Franklin Street.

City of Melbourne. (2017b), Tunnerminnerwait and Maulboyheenner public marker.

Dening, G 2006, 'Performing cross-culturally', Australasian Journal of American Studies, $25(2), 1-11$

Giroux, HA 2004, 'Cultural Studies, Public Pedagogy, and the Responsibility of Intellectuals', Communication \& Critical/Cultural Studies, 1(1), 59-79. doi:10.1080/1479142042000180935

Land, C., \& City of Melbourne 2014, 'Tunnerminnerwait and Maulboyheenner: the involvement of Aboriginal people from Tasmania in key events of early Melbourne', http://www.melbourne.vic.gov.au/SiteCollectionDocuments/tunnerminnerwait-and-maulboyheenner.pdf

Savage, G 2014, 'Chasing the Phantoms of Public Pedagogy' in J. Burdick, J. A. Sandlin, \& M. P. O’Malley (Eds.), Problematizing Public Pedagogy, Routledge, New York 